\title{
Utilization of Sludge from Majis Waste Water Treatment for the Partial Replacement of Nature Fine Aggregate in Concrete
}

\author{
Ali Mohammed Al-Shehhi \\ Ali Majid Ali Al-Marzouqi \\ Mohammed Ali Mohammed Al \\ Nofali \\ Jayaram Devaraj Kamalesini
}

\author{
Shinas College of Technology \\ Shinas College of Technology \\ Shinas College of Technology \\ Shinas College of Technology
}

\begin{abstract}
This experimental investigation is to utilize the sludge waste as a replacement of natural fine aggregate. We can introduce a sustainable construction material which is proved to be an alternative for waste disposal, helping out to free from environmental pollution. By replacing the natural fine aggregate of sludge waste it helps us to save our nature. Per day for construction site, we are using a large quantity of natural fine aggregate. This study reviews various attempts that have been made to use sludge waste as the partial replacement of fine aggregate. The fine aggregate is partially replaced by a trial mix of $5 \%, 10 \%, 15 \%, 20 \%, 25 \%$ and $30 \%$ with sludge waste .Then fresh concrete and hardened concrete is prepared by the partial replacement of fine aggregate. This process is to be done by dry condition. The mechanical and physical properties of the concrete after replacement is to be tested in the laboratory and the results are compared with the ordinary concrete. The comparison of results shows that the replace of $20 \%$ sand by sludge waste shows more compressive strength than that of the ordinary concrete with sand as fine aggregate. From the result we can understand that if the sludge contains finer particles the strength of the concrete will further increase.
\end{abstract}

\section{Introduction}

The increasing of waste water in the industrial and domestic with respect to increase in the population. This increase in the population is the more responsible for the pollution in the environment. The waste produced from the human beings and the atmosphere must be treated before disposing to the atmosphere. One of the waste aspects in our society is the wastewater sludge. Wastewater sludge is the residual material removed from wastewater treatment plant. To sustain the pollution human health and environment, suitable treatment and disposal methods are required.

Waste water treatment produce considerable quantities of sludge waste, which increases the environmental pollution and wastage of land. But on the other hand, we are producing large quantities of concrete for construction purposes. For manufacturing large quantities we have to use more natural available materials like rocks, sand, etc... Now a days, concrete is the most used manmade material in the world. The Oman construction industry alone consumes approximately 30 million tons of concrete every year and relative amount of mortar too. Therefore the demand of concrete and the required raw materials is very high. This causes hike in the cost of cement, fine and coarse aggregate. To avoid the problems like cost hike and cuts in supply of concrete and mortar, the alternate material or the partial replacement for the cement and aggregate should be developed by the recycling of waste material. This provides us economical, environment-friendly and light-weight construction products. Use of the waste materials also reduces the problems of 


\section{Journal of Student Research}

Fourth Middle East College Student Research Conference, Muscat, Sultanate of Oman

land filling, environmental resource consumption and health concern.

The wastewater in sewage plants is a collection of households, industries and storm water. These components treated together, not separated. This means that there are large amounts of pollutants in the influent wastewater which will also be in sludge. The sludge has two main components, liquid and solid. Liquid part, include water and dissolved substances.

The dissolved substances contain organic and inorganic substances.

The organic dissolved substance such as carbohydrates and fatty acid and the inorganic dissolved salts such as ammonium. The solid part of sludge contains organic and inorganic solid matter. The organic matter involves living organisms and their decomposition product. The inorganic solid matter is founded in the form of metals and nutrients.

\section{Literature Review}

"Experimental Study on Effects of Sludge Waste in Concrete" To evaluate the effect of dry sludge on concrete performance, physical and mechanical properties were studied. The waste sludge material was replace with fine and coarse aggregate in various percentages such as $50 \%, 45 \%, 40 \%$ ,35\%,30\%, 25\%,20\%,15\%, $10 \%, 5 \%, 4 \%$ and $3 \%$.Also reference concrete mix is made for comparative reasons.

"An Experimental Study on Mechanical Properties of Concrete using Sludge Ash" The aim of this project is to give a simple method of using the sludge ash in partial replacement with cement. The sludge ash retained is partly replaced with cement in concrete at different proportions. Mechanical properties such as compressive strength, tensile strength and flexural strength of the sludge concrete are determined.

“Experimental Study On Replacement Of Concrete Material By Water Treatment Plant Waste Sewage" The outcomes demonstrated that the dry sludge hindered the quality advancement and has more un favorable impact on compressive quality when it has higher natural substance and its particles got to be distinctly better. The review reasoned that the dry sludge can be utilized as a part of as an added substance to solid blends and to interlock block glue as one of the accessible transfer alternatives for Gaza Strip ooze.

"Replacement of Fine Aggregate Using Sludge in Concrete" The purpose of this study is to find an alternate source for fine aggregate. In this project concrete was tested with w/c ratio of 0.45 .The mechanical properties such as compressive strength, split tensile strength and flexural strength were tested for 7, 14 and 28 days. This experimentation holds good strength till $20 \%$ of replacement with sludge in fine aggregate. The strengths decreased when the replacement of sludge is above $20 \%$.

\section{Methodology}

Mixing of sludge with fine aggregate is to be done by the following processes. In dry method, the sludge is placed in the oven for 24 hours by maintaining the temperature of about 200 degrees Celsius. After that the material is finely grinded and mixed with the fine aggregate. 


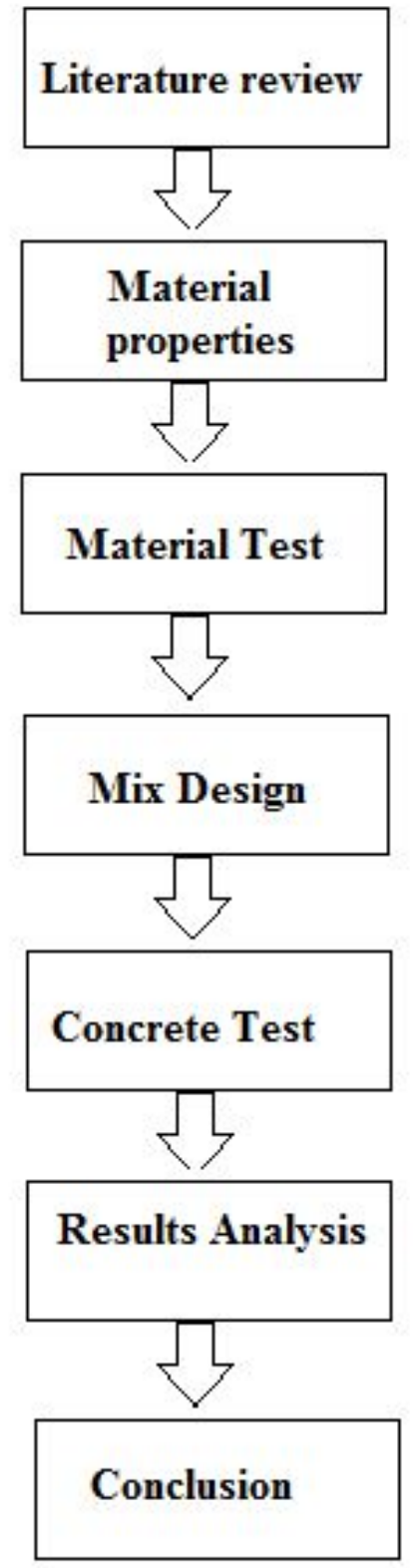

Figure 1. Methodlology

\section{Materials}

\section{Cement}

A cement is a binder, a substance used in construction that sets and hardens and can bind other materials together. Portland cement is the most common type of cement in general use around the world. SRC - 42.5 grade is used.

Sulphate Resisting Portland Cement is a type of Portland cement in which the amount of Tricalcium aluminate $(\mathrm{C} 3 \mathrm{~A})$ is restricted to lower than $5 \%$ and $(2 \mathrm{C} 3 \mathrm{~A}+\mathrm{C} 4 \mathrm{AF})$ is lower than $25 \%$. SRC can be used for structural concrete wherever OPC or PPC or Slag Cement is usable under normal conditions. 


\section{Journal of Student Research}

Fourth Middle East College Student Research Conference, Muscat, Sultanate of Oman

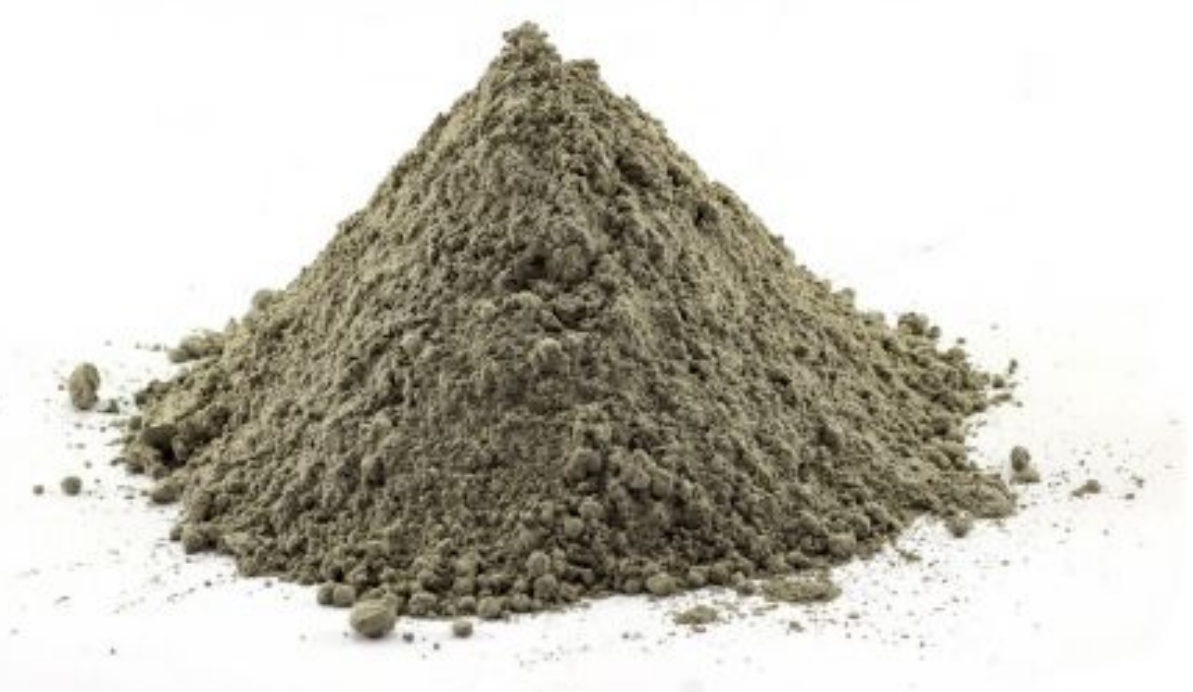

Figure 2. Cement

\begin{tabular}{|l|l|l|l|}
\hline Grade & Specific gravity & Initial setting time & Final setting time \\
\hline SRC 42.5 & 3.10 & $30 \mathrm{~min}$ & $580 \mathrm{~min}$ \\
\hline & & & \\
\hline
\end{tabular}

Table 1. Properties of cement

\section{Natural fine aggregate}

Fine aggregates play a very important role in concrete. The aggregate whose size is lesser than 5 $\mathrm{mm}$. It manages to fill the voids between the coarse aggregates.The fineness helps in increasing cohesion there by resisting segregation.

\begin{tabular}{|l|l|l|l|}
\hline Grade & Specific gravity & Initial setting time & Final setting time \\
\hline SRC 42.5 & 3.10 & $30 \mathrm{~min}$ & $580 \mathrm{~min}$ \\
\hline & & & \\
\hline
\end{tabular}

Table 2. Properties of sand

Figure 3. Sand

\section{Sludge}

All water treatment plants (WTPs) produce waste/residue known as water treatment sludge (WTS) during the purification of raw water.Silica, alumina, ferric oxide and lime constitute the major percentage of chemical components present in the sludge. Some heavy metals are also found in the sludge. The following shows the chemical properties of the sludge

\begin{tabular}{|l|l|l|l|l|l|l|l|l|}
\hline $\mathrm{Cd}$ & $\mathrm{Cr}$ & $\mathrm{Cu}$ & $\mathrm{Pb}$ & $\mathrm{Mo}$ & $\mathrm{Ni}$ & $\mathrm{Se}$ & $\mathrm{Zn}$ & $\mathrm{Hg}$ \\
\hline$<0.5$ & 115 & 134 & 18.4 & 5.8 & 281 & 19.6 & 382 & 2.42 \\
\hline & & & & & & & & \\
\hline
\end{tabular}




\section{Journal of Student Research}

Table 3. Properties of sludge

Figure 4. Sludge

\section{Coarse aggregate}

The coarse aggregate constitutes the bulk of concrete mixture and gives the dimensional stability to concrete. Size of aggregates greater than $4.75 \mathrm{~mm}$ is considered as coarse aggregate. Generally aggregates of size between $4.75 \mathrm{~mm}$ to $20 \mathrm{~mm}$ are used in concrete. The size, shape and texture of aggregates control the workability; cement content and drying shrinkage parameters. Generally smooth and rounded aggregates are preferred for concrete.

\begin{tabular}{|l|l|l|}
\hline Specific gravity & Bulk density & Fineness modulus \\
\hline 2.88 & $3.83 \mathrm{gm} / \mathrm{cc}$ & 5.68 \\
\hline & & \\
\hline
\end{tabular}

Table 4. Properties of coarse aggregate

Figure 5. Coarse aggregate

\section{Mix Design}

The Mix Design is followed by DOE method and the mix proportion is shown below

\begin{tabular}{|l|l|l|l|}
\hline Cement & Fine aggregate & Coarse aggregate & Water \\
\hline $360 \mathrm{~kg}$ & $529.2 \mathrm{~kg}$ & $1360.8 \mathrm{~kg}$ & 180 liters \\
\hline 1 & 1.47 & 3.78 & 0.5 \\
\hline & & & \\
\hline
\end{tabular}

Table 5. Proportions of materials

\section{Experiment procedure}

Several experimental investigation are carried out to check the performance of concrete by using sludge waste as the replacement of natural fine aggregate

\begin{tabular}{|l|l|l|l|l|l|l|l|l|}
\hline \multicolumn{2}{|c|}{ Mix } & S1 & S2 & S3 & S4 & S5 & S6 & S7 \\
\hline \multirow{2}{*}{ FA } & Sand & 100 & 95 & 90 & 85 & 80 & 75 & 70 \\
\cline { 2 - 9 } & Sludge & 0 & 5 & 10 & 15 & 20 & 25 & 30 \\
\hline & & & & & & & & \\
\hline
\end{tabular}

Table 6. Trial Mix proportions of replacement of fine aggregate with sludge

\section{Compression strength test}

The compressive strength of the specimen of standard size $150 \mathrm{~mm}$ x $150 \mathrm{~mm}$ x $150 \mathrm{~mm}$ cubes are tested for 7, 14 and 28 days of curing. The strength of the concrete is obtained from 7 trial mixes of 
cubes. The coarse aggregate and fine aggregate are first mixed and then cement is added with sludge in the proportions of $0,5 \%, 10 \%, 15 \%, 20 \%, 25 \%$ and $30 \%$ respectively. The water is added to the mixture and mixed well. The concrete is then poured into the cubes in three layers and tampered with tamping rod of size $12 \mathrm{~mm}$ and compacted well. The cubes are demolded and are subjected for curing. The cubes are taken out after curing period and is tested for compressive strength. Load is applied until the failure point has been reached.

Compressive strength of the specimen is calculated by,

fck $=\mathrm{P} / \mathrm{A}$

\begin{tabular}{|l|l|l|l|}
\hline Replacement Mix & 7 days N / mm2 & 14 days N / mm2 & 28 days N / mm2 \\
\hline S1 & 14.5 & 18.7 & 24.8 \\
\hline S2 & 13.6 & 18 & 23 \\
\hline S3 & 14 & 17.5 & 23.5 \\
\hline S4 & 14.7 & 18 & 25 \\
\hline S5 & 15.5 & 19.5 & 25.5 \\
\hline S6 & 14.3 & 18.5 & 24 \\
\hline S7 & 13 & 17 & 23.2 \\
\hline
\end{tabular}

Table 7. Compressive strength test

\section{Results and Investigation}

After the detailed investigation on different strength parameters has been done, the following result has been achieved.

1. The specimens added with the sludge have a significant result over the Compressive strength. The compressive strength for the specimens S5 were found to be 15.5,19.5 and 25.5 for 7 days, 14 days and 28 days respectively. The compressive strength of the materials after $20 \%$ replacement of the natural fine aggregate shows more strength, as shown in fig.6.

Figure 6. Comparison of compressive strength

\section{Conclusion}

The following conclusions have been made based on the results obtained from the experimental investigation.

1. The specimen with sludge as waste material was found to be good in compression which had the compressive strength of 25.5 after $20 \%$ replacement of natural fine aggregate by sludge.

2. Better strength was achieved with the replacement of the sludge waste in concrete. The strength has increased up to $5 \%$ when compared to that of the conventional concrete specimen.

3. Sludge can be used as an effective replacement of fine aggregate in concrete. This can reduce the usage of natural fine aggregate. By this method we can utilize more quantities of sludge waste. This is one of the way to dispose sludge waste by echo friendly means.

\section{Benefits}




\section{Journal of Student Research}

Fourth Middle East College Student Research Conference, Muscat, Sultanate of Oman

Replacement of natural sand by sludge in concrete protect the environment of Oman from land filling and contaminating the sea water by heavy metals and toxic chemicals. Save the natural aggregates for the future generations of Oman. Improve the performance of concrete.

\section{Acknowledgements}

It gives us a great sense of pleasure to present the report of the project undertaken during Semester 1 AY 2019-20. We take this opportunity to acknowledge the contribution of all faculty members of the Engineering Department Shinas College of Technology for their kind assistance and cooperation during the development of our project. We owe special debt of gratitude to Majis Company for providing the sludge from their waste water treatment plant for the Investigation. We also acknowledge our friends for their contribution in the completion of the project.

\section{References}

Bharat Nagar and Prof V. P. Bhargava were studied about "Experimental Study on Effects of Sludge Waste in Concrete" 2016.

Sukanya.M, Madhuvannthan. S, Thaarani. T, Nathiya. $P$, Nirmal. S were studied about "An Experimental Study on Mechanical Properties of Concrete using Sludge Ash" 2019.

T.Subramani and A.Anbuchezian were studied about "Experimental Study on Replacement of Concrete Material by Water Treatment Plant Waste Sewage" 2017.

Srinivasan. K, Vazhviniyan, MohanKuma r. L Palpandi. K were studied about "Replacement of Fine Aggregate Using Sludge in Concrete” 2016.

Sreehari Raj*, Sreelekshmi S were studied about "Study of Concrete by Replacing Fine Aggregate by ETP Sludge of TiO2" 2015

Anuradha Govind Karada, Dr. G. D. Awchat were studied about "A Review on Partial Replacement of Fine Aggregate by Waste Paper Sludge in Concrete” 2017, pg. 369-376 .

Meenakshipriya B, Saravanan K, Shanmugam R, Sathiyavathi S. Study of pH system in common effluent treatment plant. Mod Appl Sci 2008; 2:113e21

Elangoven C. \& Subramanian K., Reuse of alum sludge in clay brick manufacturing. Water Science \&Technology: water supply, 11 (3), 33- 341.

Andrew D. B., \& Evaggelia, P. S. (2007). Water treatment residues as clay replacement and colorant in facing bricks. Characterisation of Mineral Wastes, Resources and Processing technologies - Integrated waste management for the production of construction material - WR0115.

Badir E. H., Hanan A. F., \& Ahmed M. H. (2012). Brick Manufacture from Water Treatment Sludge and Rice Husk Ash. Australian Journal of Basic and Applied Science, 6(3): 453-461.

Sadam Hade Hussein, Kamal Nasharuddin Bin Mustapha, Zakaria Che Muda,Salmia Beddu, Verification For Modeling of Ultimate Load For Lightweight Palm Oil Clinker Reinforced Concrete Beams with Web Openings Using Response Surface Methodology. International Journal of Civil Engineering and Technology, 3(2), 2012, pp.229-240.

T.Subramani, P.Ramasamy , " Thermal Conductivity Of Fibre Filled With Ferrocement Sandwich Panels" ,International Journal of Application or Innovation in Engineering \& Management (IJAIEM) , Volume 5, Issue 5,pp. 204-215, 2016 


\section{Journal of Student Research}

Fourth Middle East College Student Research Conference, Muscat, Sultanate of Oman

T.Subramani, P.Sakthivel , " Experimental Investigation On Flyash Based Geopolymer Bricks" , International Journal of Application or Innovation in Engineering \& Management (IJAIEM) , Volume 5, Issue 5, pp. 216-227, 2016 